\title{
Revisiting Swallowed Troubles: Intestinal Complications Caused by Two Magnets-A Case Report, Review and Proposed Revision to the Algorithm for the Management of Foreign Body Ingestion
}

\author{
Viju Vijaysadan, MD, Maria Perez, DO, and David Kuo, MD
}

Accidental ingestion of foreign bodies and its management is a common problem seen more in the pediatric population than in adults. A review of the literature suggests that endoscopic removal of foreign bodies is curative for objects located in the cricopharynx or upper esophagus. Foreign bodies passed into the stomach can usually be observed for development of symptoms, because $80 \%$ of them would be spontaneously passed.

However, ingestion of metallic foreign bodies involving coins or button-type batteries may require an aggressive approach. A few cases of intestinal obstruction due to magnet ingestion have been reported in Japan, China, and Korea where magnets are used for treatment in traditional medicine. ${ }^{1-5}$ When more than one magnet is ingested they can be attracted to each other through the intestinal wall, causing necrosis and intestinal perforation or fistula, so they should be removed while they are still accessible with endoscope.

We report a case for the first time in the United States of intestinal obstruction and fistula formation due to ingestion of more than one magnet. We feel that early endoscopic removal of magnets or a magnet along with a magnetic foreign body is safe and should be the choice of management. The

This article was externally peer-reviewed.

Submitted 10 January 2006; revised 18 March 2006; accepted 27 March 2006.

From the University of Medicine and Dentistry of New Jersey, Combined Medicine-Pediatrics, Atlantic Health System, Summit, NJ.

Consent was obtained from the mother of the patient and witnessed by Viju Vijaysadan, MD.

Corresponding author: Viju Vijaysadan, MD, University of Medicine and Dentistry of New Jersey, Combined Medicine-Pediatrics, 99 Beauvoir Avenue, Summit, NJ 07901 (E-mail: viju@earthlink.net). author proposes an algorithm for management of foreign body ingestion focusing on early retrieval of magnetic foreign bodies.

\section{Case}

An 11-year old boy presented with a three-week history of nausea, vomiting, and burning epigastric pain. He had been treated for Streptococcus A pharyngitis by his pediatrician and had been seen in the emergency department previously with a negative work-up. At admission, vital signs were stable but the patient was visibly uncomfortable, lying on his left side with bilateral lower extremities flexed. Physical examination revealed abdominal tenderness with light palpation and decreased bowel sounds in the right and left lower quadrants. Leukocyte count was $13,900 / \mathrm{mm}^{3}$, hemoglobin and hematocrit were slightly elevated, and all other laboratory findings were within normal limits. Radiograph and CT scan of abdomen and pelvis confirmed the presence of two foreign bodies in the pelvis with bowel obstruction (Figures 1 and 2). After multiple rounds of questioning, the patient revealed that he had swallowed two magnets from a toy approximately 1 month before. A surgical consult was called that resulted in an exploratory laparotomy. Operative report of our patient describes fistulae formation at ileoileal level involving a " $U$ " turn region of ileum and proximal jejunum and distal ileum that fistulized through the mesentery of terminal ileum. The procedure involved division, debridement to healthy bowel and closure of jejunoileal fistula, enterotomy for foreign body removal, and reinforcement at ileoileal fistula after division. The specimens were examined by the pathologist and confirmed to be consistent with fis- 


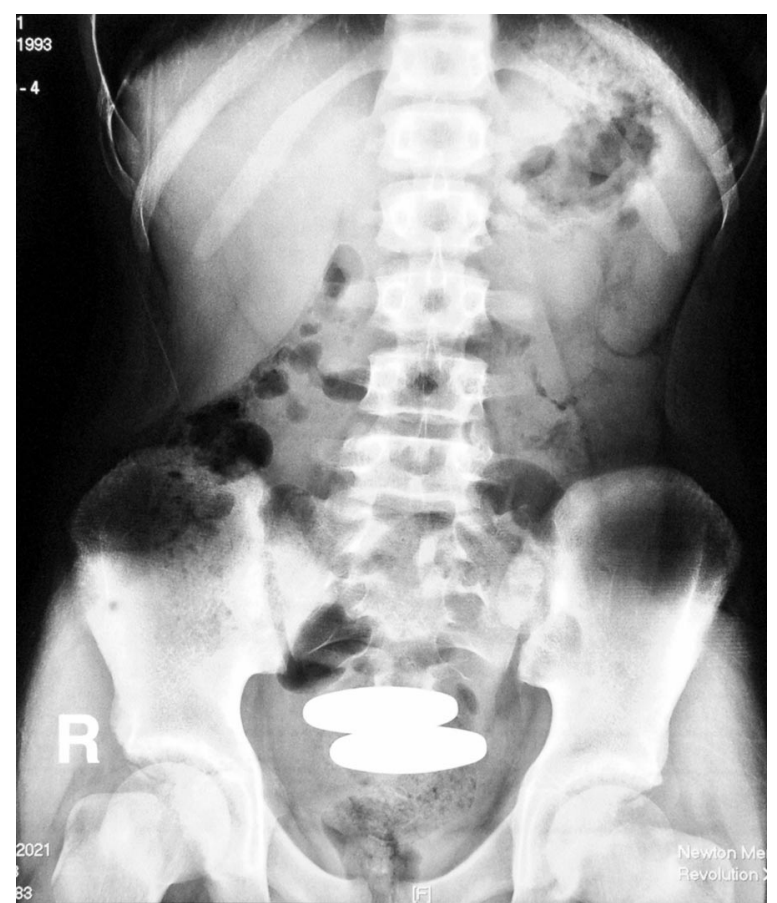

Figure 1. Radiograph of the abdomen showing the magnets and bowel obstruction. tula formation. The foreign body was identified and found to be 2 grayish tan magnetic torpedoshaped metal fragments measuring $5.7 \times 1.5 \times 1.5$ $\mathrm{cm}$. A jejunoileal fistula caused by these magnets was found. The magnets were removed, and the fistula was repaired. The patient's postoperative hospital course was unremarkable, and he was discharged on the 8th postoperative day.

\section{Discussion}

Foreign bodies in the alimentary tract of children are commonly managed by pediatricians and surgeons. Most foreign bodies pass readily into the stomach and travel the remainder of the gastrointestinal tract without difficulty; nevertheless, the experience frequently is traumatic for the patient, the parents, and the physician, who must await the removal or the ultimate passage of the foreign body. ${ }^{6}$ Ten to $20 \%$ of ingested foreign bodies will fail to pass through the entire gastrointestinal tract. ${ }^{9}$ Any foreign body that remains in the tract may cause obstruction, perforation or hemorrhage,

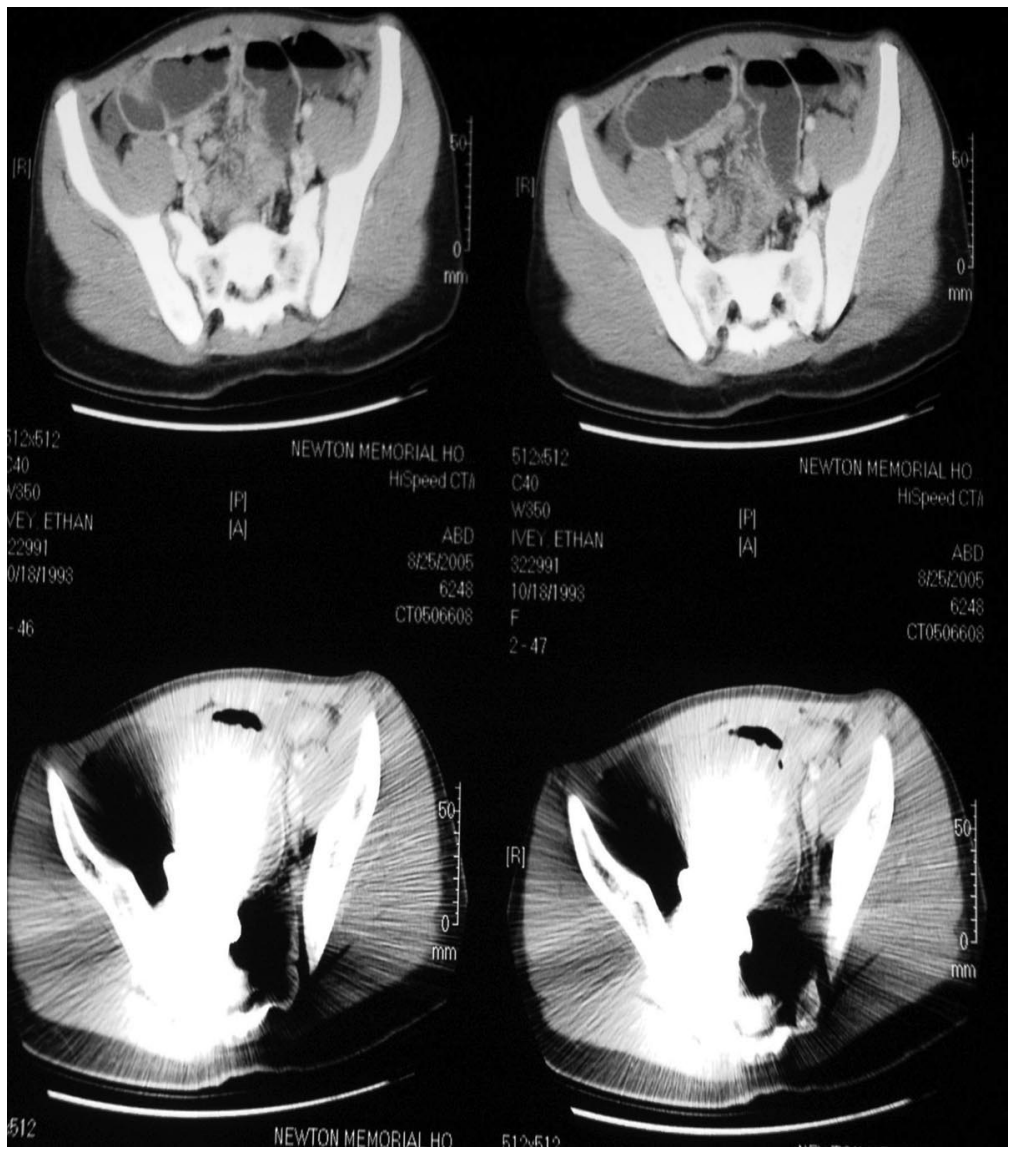

Figure 2. CT scan of the abdomen showing bowel obstruction and distortion by the magnets. 
Table 1. Points of Gastrointestinal Tract Most Likely to Cause Delay

\begin{tabular}{ll}
\hline Esophagus & $\begin{array}{c}\text { Post cricoids, aortic arch, left main } \\
\text { bronchus and diaphragm } \\
\text { Pylorus }\end{array}$ \\
$\begin{array}{l}\text { Stomach } \\
\text { Duodenum }\end{array}$ & $\begin{array}{r}\text { Junction of second and third portion } \\
\text { and the terminal portion } \\
\text { Meckel's diverticulum, ileo-cecal region }\end{array}$ \\
$\begin{array}{l}\text { Small intestine } \\
\text { Large intestine }\end{array}$ & $\begin{array}{r}\text { Flexures and haustration of large } \\
\text { intestine and rectum }\end{array}$ \\
Anatomic & Diverticula, sacculation, annular \\
abnormality & pancreas, adhesions
\end{tabular}

and fistula formation. Less than $1 \%$ cause perforations $^{7}$ that are probably caused by sharp objects or by erosion. The duration of an ingested foreign body in the gastrointestinal tract and the risk of perforation or obstruction are associated with the anatomy and structure of the gastrointestinal tract. The areas in the gastrointestinal tract where obstruction commonly occurs are shown in Table $1 .^{7}$

\section{Diagnosis}

The diagnosis depends on the clinical history of foreign body ingestion (very important in radiolucent foreign bodies) invariably with confirmation by radiograph or CT scan appearance and upper endoscopy. Plain radiograph of neck and chest in both anteroposterior and lateral views is required in all cases in addition to abdominal films. A CT scan is more informative if available or if radiographs are inconclusive. Contrast studies with Gastrograffin may be required in excluding or locating the site of impaction of the foreign body as well as determining the level of a perforation. Using contrast is important in identifying and locating foreign bodies if intrinsically non-radiopaque substances, such as wooden checkers or fish and chicken bones are ingested. ${ }^{8}$

\section{Risk Factors}

The foreign bodies that obstruct the esophagus are relatively different from those further down the gastrointestinal tract. The esophagus is a passive and inadaptable organ in which peristalsis may not be sufficient to pass objects that are large. For the same reason, perforation from a foreign body is more likely to occur in the esophagus than in the rest of the tract. The resultant edema from local trauma may cause greater obstruction making later manipulation increasingly difficult and risky. Per-
Table 2. Symptoms in Order of Frequency

\begin{tabular}{lc}
\hline Adults & \multicolumn{1}{c}{ Children } \\
\hline $\begin{array}{l}\text { 1. Pain or discomfort on } \\
\text { swallowing }\end{array}$ & 1. Refusal to take food \\
$\begin{array}{l}\text { 2. Persistent sensation of FB on } \\
\text { swallowing }\end{array}$ & 2. Increased salivation \\
$\begin{array}{l}\text { 3. Blood-stained saliva } \\
\begin{array}{l}\text { 4. History of gagging or } \\
\text { choking }\end{array}\end{array}$ & $\begin{array}{l}\text { 4. Vomallowing } \\
\text { Switing }\end{array}$ \\
\hline
\end{tabular}

foration of the esophagus is dangerous because it may lead to parapharyngeal or retropharyngeal abscess with possible descending mediastinitis. Rarely a fistula may be formed with an adjacent vessel.

Studies have shown that the cervical esophagus is the most common site of impaction and complications in perforation followed by upper thoracic esophagus, pyriform fossa, and valecula. ${ }^{9}$

Complications of esophageal foreign body occur more often in adults than in the pediatric population $^{8}$ and includes but is not limited to perforation leading to retropharyngeal abscess, subcutaneous emphysema, mediastinitis, retroesophageal abscess, lung abscess, and esophago-aortic fistula and tracheo-esophageal fistula-fortunately rare. Many patients complain of persistent hoarseness, dysphagia, and pain for weeks following the removal.

A foreign body arrested in the esophagus should be removed as soon as the diagnosis is made for the above reasons. ${ }^{8}$ Please refer to Table $2^{8}$ for the symptoms in order of frequency in adults and children.

Once the foreign body passes the esophagogastric junction into the stomach, it will usually pass through the pylorus ${ }^{10}$; however, surgical removal is indicated if the foreign body has sharp points or if it remains in one location for more than 4 to 5 days especially in the presence of symptoms. A decision should be based on the nature of the foreign body in those cases, as to whether a corrosive or toxic metal in ingested. ${ }^{11}$ Magnets or a magnet along with a magnetic object should be emergently removed.

The length of the foreign body is also a risk factor for obstruction, particularly in children under 2 years of age because they have considerable difficulty in passing objects longer than $5 \mathrm{~cm}$ through the duodenal loop into the jejunum. In infants, foreign bodies 2 or $3 \mathrm{~cm}$ in length may also become impacted in the duodenum. ${ }^{12}$ Although the 
literature doesn't document a particular length beyond which a foreign body is likely to cause perforation or obstruction, it has been recommended objects longer than $5 \mathrm{~cm}$ be endoscopically removed. ${ }^{13,14}$

The number of objects does not appear to be a risk factor for perforation, ${ }^{15}$ which may not true, when it comes to magnetic foreign bodies. Even nonmagnetic items may be more likely to cause obstruction if a large number is ingested. The largest number of foreign bodies reported in the literature was ingested by a woman with a psychiatric disorder, ${ }^{16}$ who required surgical removal of 2533 objects (none were magnetic) without any evidence of bleeding, ulceration, or perforation.

The chemical nature of the ingested foreign body is of importance when it includes a substance that can cause mucosal injury. The results of a national button battery ingestion study revealed that $89.9 \%$ of 119 ingested button batteries were spontaneously passed in 12 to 14 days. Endoscopic retrieval of button batteries failed in $66.6 \%$ of cases, ${ }^{17,} 18$ usually due to migration of the battery distally during air insufflation at endoscopy. Rarely, ingested batteries may leak, causing mucosal burns. This has been documented most often in the esophagus, with production of secondary tracheoesophageal fistula and perforation. ${ }^{19-22}$

Consideration of the underlying comorbid states were first done by McPherson et al who examined the contribution of chronic intestinal obstruction due to hernia or postoperative adhesions to the risk of intestinal perforation by foreign bodies. ${ }^{23}$ There are, however, no studies examining pre-existing intestinal disease (eg, Crohns, UC, and pseudo-obstruction) and their possible contribution to foreign body impaction or perforation. Such risk factors nevertheless are well established indications for early endoscopic and possible surgical interventions. $^{24}$

In cases when objects fail to pass the tract in 3 to 4 weeks, reactive fibrinous exudates due to the foreign body may cause adherence to the mucosa, and objects may migrate outside the intestinal lumen to unusual locations such as the hip joint, bladder, liver, and peritoneal cavity. ${ }^{25}$ The length of time between ingestion and presentation may vary from hours to months and in unusual cases to years, as in the case reported by Yamamoto of an 18 $\mathrm{cm}$ chopstick removed from the duodenum of a 71 -year-old man, 60 years after ingestion. ${ }^{26}$

\section{Treatment}

Occasionally objects that reach the colon may be expelled after enema administration. However, stool softeners, cathartics and special diets are of no proven benefit in the management of foreign bodies. ${ }^{27}$ Catharsis may be dangerous as it stimulates forceful contractions and drives the object against the intestinal wall.

Early intervention is required if there are risk factors for complications such as bleeding, mucosal trauma, perforation (of the esophagus), and aspiration of the object as it is removed from the posterior pharynx. The problems of aspiration and perforation can be averted by use of protective techniques during foreign body removal. ${ }^{28}$ The risks of endoscopic removal of objects are the inherent risks associated with endoscopy in addition to the dangers of extracting the object. A 1974 survey of 211,410 upper endoscopic examinations revealed an overall complication rate of 1.32/ $1000 .^{29}$ Among serious cases of morbidity, cardiopulmonary complications are most frequent (1/1638) followed by perforation (1/3300) and bleeding (1/3500). Since 1974, there has been tremendous improvement in techniques and instruments, and safer anesthetics making these safer with minimal complications. Methods to deal with foreign bodies include suture technique, the double snare technique, combined forceps/snare technique for long and sharp foreign bodies, along with newer equipment, such as retrieval nets and variety of specialized forceps. ${ }^{30}$

The management of patients who have ingested magnetic foreign bodies poses unusual challenges, as with our patient. Complications are caused by magnetic force, because magnets attract each other, holding the intestinal walls between them. The affected area of the wall then becomes compressed and necrotic, resulting in intestinal perforation or fistulae. Moreover, if the mesenteric vessels are involved between the walls, intraperitoneal hemorrhage may occur.

Reports describing the ingestion of metallic foreign bodies have been made but for magnetic ingestion until $1995 .{ }^{31}$ Our review of the literature indicates a report in Japanese as early as 1991 in Shonika (Pediatrics of Japan). These case reports are from Japan ${ }^{2}$ and Korea ${ }^{3}$ where magnets are used for treatment of stiffness of neck or shoulders, improvement of circulation. These magnets are small enough to be swallowed easily and can cause 


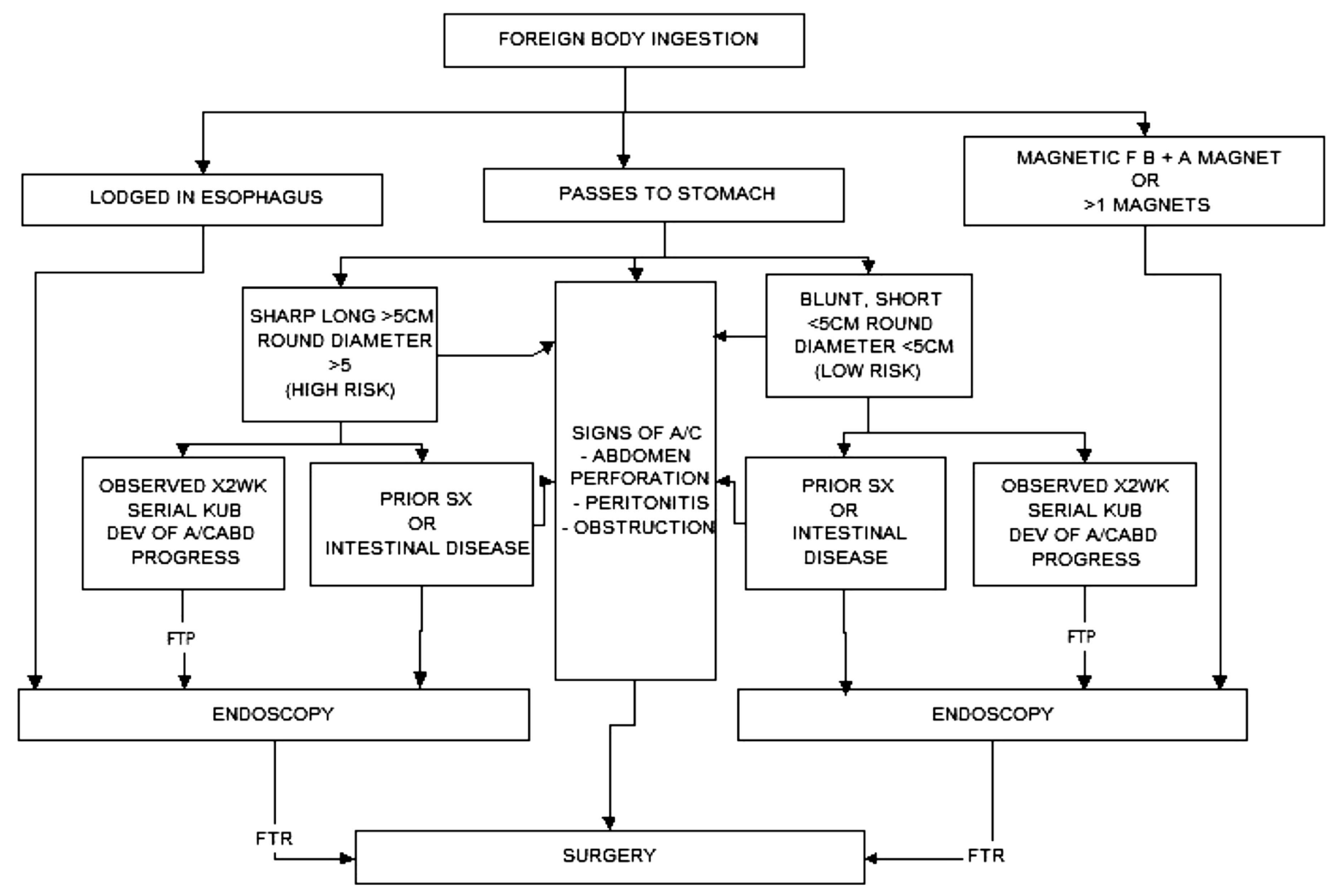

FTP $=$ Failure to Progress

FTR $=$ Failure to retrieve

SX $=$ Surgery

Figure 3. Algorithm for management of ingested foreign bodies.

problems more if than one is swallowed. Two other case reports from Japan discuss strangulated intestinal obstruction with an ileoileal fistula ${ }^{4}$ and 4 perforations. $^{5}$

Although it is clear that immediate endoscopic retrieval of foreign bodies lodged in the esophagus is indicated, the current approach to management of foreign bodies which have passed the esophagus depends on the presence or absence of abdominal symptoms, peritonitis, the rate of progression, and the nature of the object.

An algorithm for management of foreign body ingestion was developed and published in 1984 by Selivanov et $\mathrm{al}^{32}$ and later modified by Henderson et al in $1987 .{ }^{10}$ The algorithm took into account the size of the ingested foreign body and existence of chronic intestinal disease. We suggest a modification be made to the algorithm to account for magnetic objects (Figure 3).

A review of the literature involving magnetic foreign bodies would make it clear that with one magnet $<5 \mathrm{~cm}$ devoid of sharp edges without co- existence of other metallic objects and underlying intestinal illness, observation is indicated. However, when more than one magnet is ingested, or a magnet along with another magnetic foreign body is ingested they should be removed while they are still accessible with an endoscope. If they have passed beyond the pylorus at the time of admission and can't be retrieved, surgical intervention is imperative because of the potential of opposing magnets causing bowel complications. An emergency explorative laparotomy and removal of the magnet or magnets with a magnetic foreign body in addition to necessary repairs should be the rule.

\section{References}

1. Kubota Y, Tokiwa K, Tanaka S, Iwai N. Intestinal obstruction in an infant due to magnet ingestion. Eur J Pediat Surg 1995;5:119-21.

2. Honzumi M, Shigemori C, Ito H, Mohri Y, Urata H, Yamamoto T. An intestinal fistula in a 3-year-old child caused by the ingestion of magnets: report of a case. Surgery Today. Jpn J Surg 1995;25:552-3. 
3. Chung JH, Kim JS, Song Y'T. Small bowel complication caused by magnetic foreign body ingestion of children: two case reports: J Pediat Surg 2003;38: $1548-50$.

4. Takahashi M, Kataoka A, Kushida T, Sato O, Hakozaki H, Suzuki M. A case of intestinal obstruction in children due to magnets (in Japanese). Dohnan Igakkaishi 1989;24:276-8.

5. Ohkubo M, Kaku H, Uhara $\mathrm{H}$, et al. A case of intestinal perforation due to multiple magnet ingestion (in Japanese). Shonika (Pediatrics of Japan) 1991;32:743-5.

6. Eldridge WW, Jr. Foreign bodies in the gastrointestinal tract. JAMA 1961;178:665-7.

7. Perelman H. Tooth pick perforations of the gastrointestinal tract. J Abdom Surg 1965;51-3.

8. Maglinte DDT, Taylor SD, Ng AC. Gastrointestinal perforation by chicken bones. Radiology 1979; 130:597-9.

9. Nandi P, Ong GB. Foreign body in oesophagus: review of 2394 cases. Br J Surg 1978;65:5-9.

10. Henderson CT, Engel J, Schlesinger P. Foreign body ingestion: review and suggested guidelines of management. Endoscopy 1987;19:68-71.

11. Seo JK. Endoscopic management of gastrointestinal foreign bodies in children. Indian J Pediatr 1999;66 (1 Suppl):S75-80.

12. Erbes J, Babbitt DP. Foreign bodies in the alimentary tract of infants and children. Appl Ther 1965;7: 1103-9.

13. Soergel KH, Hogan WJ, Solammedevi SV, et al. Therapeutic endoscopy. Hosp Pract 1983;18:81-92.

14. Christie DL, Ament ME. Removal of foreign bodies from esophagus and stomach with flexible fiberoptic panendoscope. Pediatrics 1976;57:931-4.

15. Solammadevi SV, Hundley RF. Removal of multiple foreign objects from the stomach. Gastrointest Endosc 1983;29:64.

16. Chalk SG, Foucar HD. Foreign bodies in stomach: Report of a case in which more than 2500 foreign bodies were found. Arch Surg 1928;16:494-500.
17. Litovitz, TL. Battery ingestions: product accessibility and clinical course. Pediatrics 1985;75:469-73.

18. Litovitz, TL. Button battery ingestions: a review of 56 cases. JAMA 1983;249:2495-3500.

19. Blatnik BS, Toohill RJ, Lehman RH. Fatal complications from an alkaline battery foreign body in the esophagus. Ann Otol Rhinol Laryngol 1977;86:611-5.

20. Shabino CL, Fineberg AN. Esophageal perforation secondary to alkaline battery ingestion. JACEP 1979;8:360-2.

21. Votteler TP, Nash JC, Rutledge JC. The hazard of ingested alkaline disk batteries in children. JAMA 1983;249:2504-6.

22. Litovitz TL. as in reference 14 and 15.

23. McPherson RC, Karlan M, Williams RD. Foreign body perforation of intestinal tract. Am J Surg 1957; 94:564-6.

24. Spitz L. Management of ingested foreign bodies in childhood. Br Med J 1971;4:469-72.

25. Carp L. Foreign bodies in the intestine. Ann Surg 1927;85:575-91.

26. Yamamoto M, Mizuno H, Sugawara V. A chopstick is removed after 60 years in the duodenum. Gastrointest Endosc 1985;31:51-2.

27. MacManus JE. Perforations of the intestine by ingested foreign bodies. Am J Surg 1941;53:393-402.

28. Spurling TJ, Zaloga GP, Richter JE. Fiber endoscopic removal of gastric foreign body with overtube technique. Gastrointest Endosc 1983;29:226-7.

29. Mandelstam P, Sugawa C, Silvis SE, et al. Complications associated with esophago duodenoscopy and with esophageal dialatation. Gastrointest Endosc 1976;23:16-9.

30. Kay M, Wyllie R. Pediatric foreign bodies and their management. Curr Reports 2005;7:212-8.

31. Kubota Y, Tokiwa K, Tanaka S, Iwai N. Intestinal obstruction in an infant due to magnet ingestion. Eur J Pediatr Surg 1995;5:119-21.

32. Selivanov V, Sheldon GF, Cello JP, Crass RA. Management of foreign body ingestion. Ann Surg 1984; 199:187-91. 